\title{
Application of FTIR spectroscopy and multivariate calibration for analysis of curcuminoid in syrup formulation
}

\author{
Niken K. Prabaningdyah ${ }^{1,2}$, Sugeng Riyanto', Abdul Rohman ${ }^{1,3^{*}}$ \\ 'Department of Pharmaceutical Chemistry, Faculty of Pharmacy, Gadjah Mada University, Yogyakarta, 55281, Indonesia. \\ ${ }^{2}$ The National Agency of Drug and Food Control, District of Yogyakarta, Republic of Indonesia. \\ ${ }^{3}$ Research Center of Halal Products, Gadjah Mada University, Yogyakarta, 55281, Indonesia.
}

\section{ARTICLE INFO \\ Article history: \\ Received on: $10 / 12 / 2017$ \\ Accepted on: 13/02/2018 \\ Available online: 30/03/2018}

Key words:

FTIR spectroscopy, curcumin,

demethoxycurcumin, partial

least square, syrup.

\begin{abstract}
Curcuminoid, the main components in Curcuma species, is responsible for several biological activities including antioxidant and hepatoprotective effect, therefore fast and reliable analytical method is required for curcuminoid determination. The objective of this study was to develop Fourier transform infrared (FTIR) spectroscopy in combination with multivariate calibration of partial least square (PLS) and principle component regression (PCR) for quantitative analysis of curcumin (CUR) and desmethoxycurcumin (DMC) in syrup sample containing extract of Curcuma xanthorriza (temulawak). Syrup samples were directly scanned using FTIR spectrophotometer with attenuated total reflectance (ATR) sampling technique at wavenumbers $4000-650 \mathrm{~cm}^{-1}$ and its spectra were correlated with contents of CUR and DMC determined using high performance liquid chromatography. PLS offered better prediction model for the relationship between actual values of CUR and DMC and FTIR predicted values using absorbances at wavenumbers of 3004-974 $\mathrm{cm}^{-1}$ than that using PCR. PLS calibration model yielded $R^{2}$ of 0.9999 (calibration) and 0.9976 (for validation) for such correlation. The errors in calibration and validation expressed by root mean square error of calibration (RMSEC) and root mean square error of prediction (RMSEP) were low, i.e. 0.0014 (RMSEC) and 0.0017 (RMSEP), respectively. FTIR spectroscopy in combination with PLS provide fast, accurate and precise method for determination of CUR and DMC in syrup samples.
\end{abstract}

\section{INTRODUCTION}

Curcumin (CUR) and desmethoxycurcumin (DMC) with chemical structures as in Figure 1 is main components of curcuminoid present in Curcuma xanthooriza (temulawak in Indonesia) (Lechtenberg et al., 2004). Both CUR and DMC was responsible for several biological activities including antioxidant, antibacterial, antiinflamation and anticancer activities (Duvoix et al., 2005; Shishodia, 2005). Both compounds were also used as chemical markers for quality assurance of pharmaceutical formulation using Curcuma species as main components (Li et al., 2011). Many traditional medicine and supplement containing

${ }^{*}$ Corresponding Author

Abdul Rohman, Department of Pharmaceutical Chemistry, Faculty of Pharmacy, Gadjah Mada University, Yogyakarta, 55281, Indonesia. E-mail:abdul_kimfar@ugm.ac.id curcuminoid had been produced in the form of tablet, syrup and also suspension. Therefore, reliable analytical method should be applied in order to assure product quality (Singh et al., 2014).

Several methods based on chromatographic methods such as thin layer chromatography (Péret-Almeida et al., 2005), high performance liquid chromatography using detectors of UV-vis (Korany et al., 2013), photodiode array (Korany et al., 2013), liquid chromatography-mass spectrometry (Jiang et al., 2006) and capillary electrophoresis (Anubala et al., 2016) were reported for analysis of CUR and DMC in different samples. However, this chromatographic method was time consuming and involving extensive laborious activities, thus, fast, simple and reliable analytical method for analysis of CUR and DMC in pharmaceutical formulation was highly needed (Tanaka et al., 2008). One of the potential method developed as alternative chromatographic technique was Fourier transform infafred (FTIR) spectroscopy (Rohman, 2012).

FTIR spectroscopy is fast and simple method for analysis of curcuminoid in any types of samples. FTIR spectroscopy 
at near region has been developed for analysis of CUR, DMC, bisdemethoxycurcumin and total curcuminoid, analysis curcuminoid in ethanolic extract of Curcuma longa (Tanaka et al., 2008), and for analysis of ethanolic extract of Curcuma xanthorriza in mid infrared region (Lestari et al., 2017). In our best knowledge, there is no publication reports regarding the application of FTIR spectroscopy for analysis of CUR and DMC in pharmaceutical formulation. The objective of this study was to develop FTIR spectroscopy in combination with multivariate calibration of PLS and PCR for assay of CUR and DMC in syrup samples.<smiles>COc1cc(/C=C/C(=O)CC(=O)/C=C/c2ccc(O)c(OC)c2)ccc1O</smiles><smiles>COc1cc(/C=C/C(=O)CC(=O)/C=C/c2ccc(O)c(O)c2)ccc1O</smiles>

Fig. 1: The chemical structures of curcumin (CUR) and demethoxycurcumin (DMC).

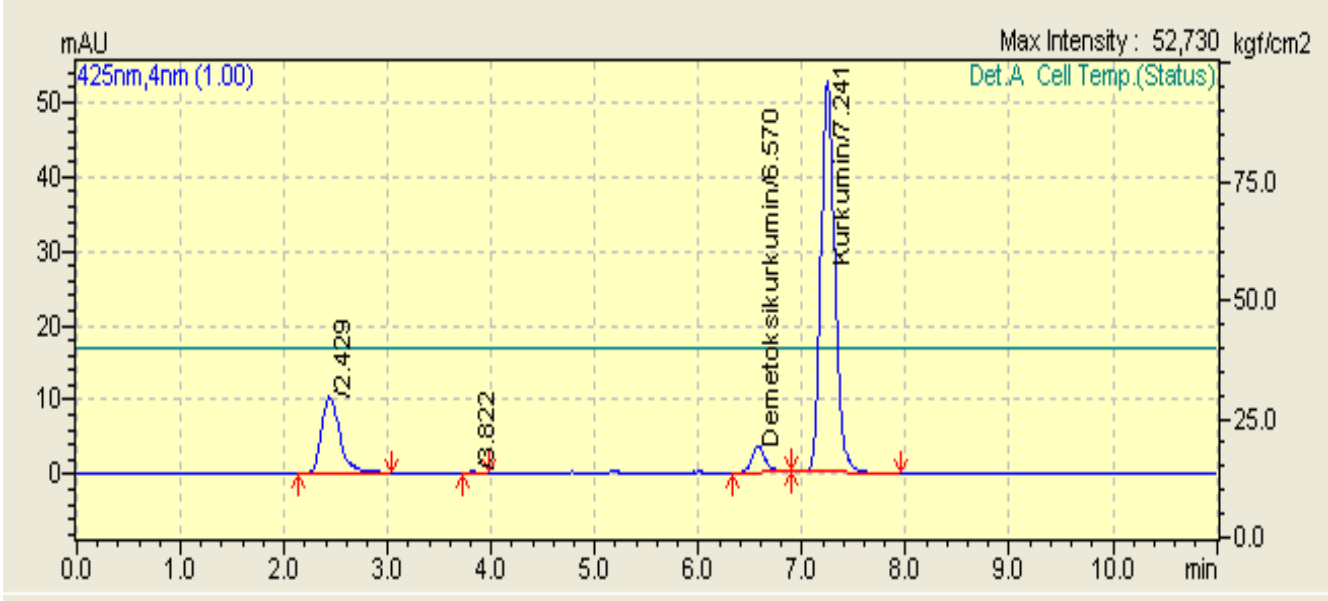

Fig. 2: Typical HPLC chromatogram of syrup samples containing Curcuma extract. CUR was stated as Kurkumin (RT. 7.241 min), DMC was stated as Demetoksikurkumin (RT. $6.570 \mathrm{~min}$ ).

\section{MATERIALS AND METHODS}

Curcumin and demethoxycurcumin were isolated from curcuminoid purchased from E. Merck (Darmstadt, Germany). Isolation was performed using method as described in PéretAlmeida et al. (2005). To check the purity of both CUR and $\mathrm{DMC}$, thin layer chromatography (TLC) and high performance liquid chromatography (HPLC) were used. The samples of syrup formulations were purchased around Yogyakarta, Indonesia. The sample placebo was given by PT. SOHO Pharmaceutical Industry
(Jakarta, Indonesia).

\section{HPLC analysis}

HPLC analysis was performed using Shimadzu HPLC instrument-LC-20AD (Japan) equipped with Rheodyne $7725 \mathrm{i}$ injection valve with a $20 \mu \mathrm{L}$ loop volume and Binary gradient pump was used. The detector used was photodiode array (Shimadzu, SPD-M20A) operated at a wavelength of 425 $\mathrm{nm}$. Data were acquired and processed by using LC-solution 
software. Chromatographic separation was performed using RP 18 Waters ${ }^{\circledR} X$-Bridge $(250 \mathrm{~mm} \times 4.6 \mathrm{~mm}$ i.d.; $5 \mu \mathrm{m})$ as reported by Prabaningdyah et al. (2017). The column temperature was set up at $40^{\circ} \mathrm{C}$. The mobile phase composition was acetonitrile-acetic acid $4.08 \%(49: 51 \mathrm{v} / \mathrm{v})$ delivered isocratically at flow rate 1.04 $\mathrm{mL} / \mathrm{min}$. For sample preparation, syrup samples $(5.0 \mathrm{~mL})$ were accurately taken and transferred into volumetric flask $100 \mathrm{ml}$. The sample was added with $50 \mathrm{~mL}$ mobile phase, shaken vigorously and made until volume with mobile phase. A- $4.0 \mathrm{~mL}$ of this solution was taken and diluted until $20 \mathrm{~mL}$, filtered using $0.45 \mu \mathrm{m}$ filter, and injected into HPLC system.

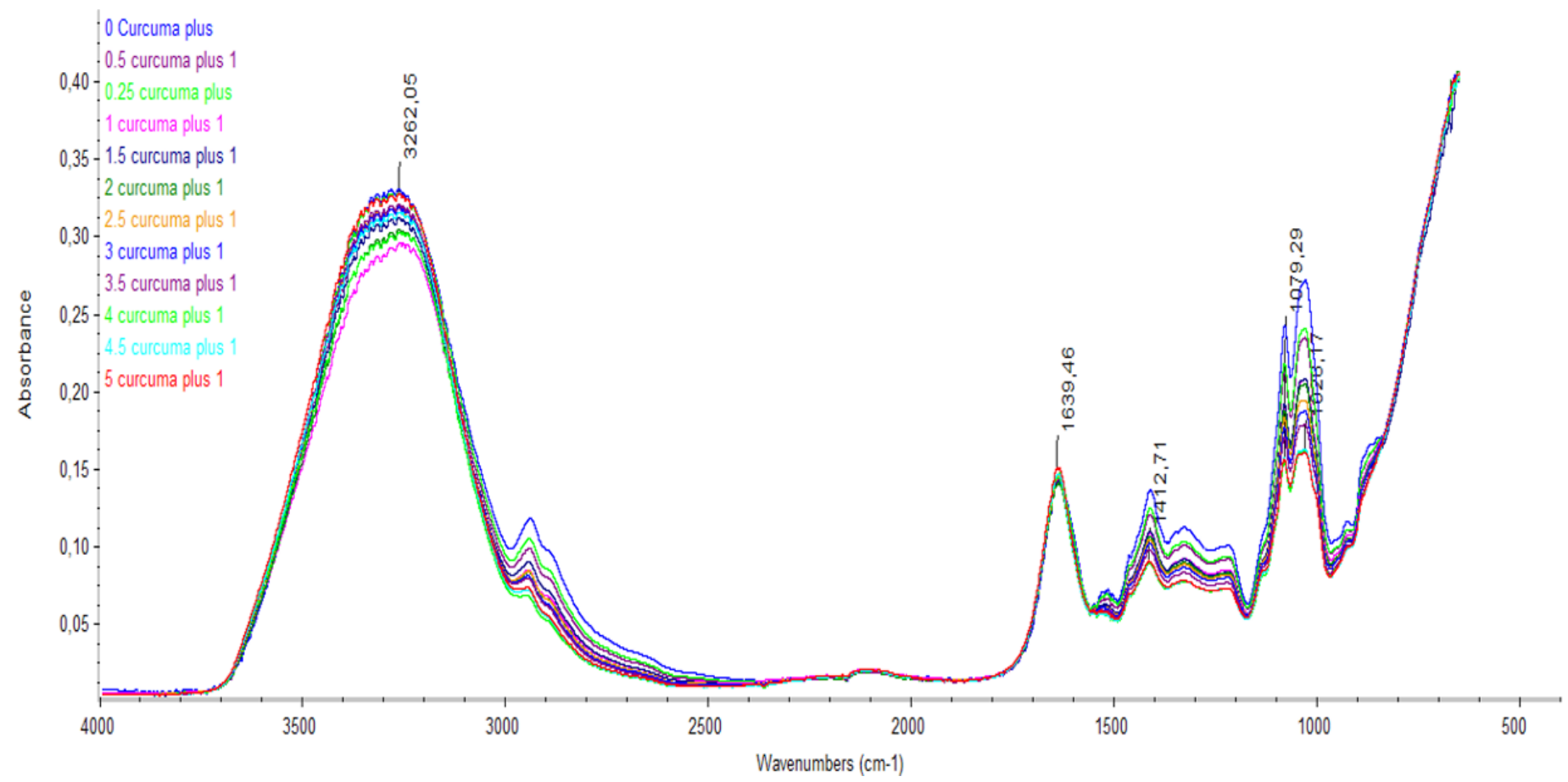

Fig. 3: The overlay of FTIR spectra of syrup samples containing curcuma extract scanned at mid infrared region $\left(4000-650 \mathrm{~cm}^{-1}\right)$.

Table 1: The contents of CUR and DMC in syrup samples, analyzed using HPLC previously validated method.

\begin{tabular}{ccc}
\hline Sample amount $(\mathrm{g})$ & CUR $(\mathrm{mg} / \mathrm{g})$ & DMC $(\mathbf{m g} / \mathbf{g})$ \\
\hline 0.2693 & 0.0262 & 0.0018 \\
0.5096 & 0.0327 & 0.0024 \\
1.0584 & 0.0698 & 0.0050 \\
1.5075 & 0.0930 & 0.0066 \\
2.0106 & 0.0977 & 0.0071 \\
2.5058 & 0.1414 & 0.0101 \\
3.0022 & 0.1841 & 0.0128 \\
3.5315 & 0.2364 & 0.0164 \\
4.0311 & 0.2523 & 0.0175 \\
4.5211 & 0.2677 & 0.0192 \\
5.0521 & 0.3203 & 0.0226 \\
\hline
\end{tabular}

\section{Analysis using FTIR spectroscopy}

The syrup samples were directly placed on Attenuated Total Reflectance (ATR) accessory composed of zinc selenide (ZnSe) crystal as sampling handling technique at controlled ambient temperature $\left(25^{\circ} \mathrm{C}\right)$. All FTIR spectra were scanned using a FTIR spectrophotometer (Nicolet 6700 FTIR spectrometer, Thermo Nicolet Corp, Madison, WI), equipped with deuterated triglycinesulphate (DTGS) detector and beam splitter of potassium bromide $(\mathrm{KBr}) / \mathrm{Germanium}$. The instrument was connected to software of the OMNIC operating system (Version 7.0, Thermo Nicolet, Madison, WI). Spectra of FTIR were scanned in wavenumbers region of $4000-650 \mathrm{~cm}^{-1}$ with resolution of $4 \mathrm{~cm}^{-1}$ and number of scanning of 32 . All spectra were calibrated using background of air spectrum as reference. After every scan, a new reference air background spectrum was taken. These spectra were recorded absorbance values at each data point in triplicate. 
Table 2: The performance of partial least square (PLS) and principle component regression (PCR) for modelling the actual values of curcumin and demethoxycurcumin as determined with HPLC and FTIR predicted values.

\begin{tabular}{|c|c|c|c|c|c|c|c|c|c|c|c|}
\hline \multirow{3}{*}{ Multivariat } & \multirow{3}{*}{ Wave Number $\left(\mathrm{cm}^{-1}\right)$} & \multirow{3}{*}{$\begin{array}{c}\text { Spectral } \\
\text { treatment }\end{array}$} & \multirow{3}{*}{$\begin{array}{c}\text { Number } \\
\text { of Factor }\end{array}$} & \multicolumn{4}{|c|}{ Curcumin } & \multicolumn{4}{|c|}{ Demethoxycurcumin } \\
\hline & & & & \multicolumn{2}{|c|}{ Calibration } & \multicolumn{2}{|c|}{ Validation } & \multicolumn{2}{|c|}{ Calibration } & \multicolumn{2}{|c|}{ Validation } \\
\hline & & & & $R^{2}$ & RMSEC & $R^{2}$ & RMSEP & $R^{2}$ & RMSEC & $R^{2}$ & RMSEP \\
\hline \multirow{9}{*}{ PLS } & $1504-844$ & Normal & 4 & 0.9975 & 0.00725 & 0.9854 & 0.00699 & 0.9999 & 0.000687 & 0.9920 & 0.000587 \\
\hline & $1504-844$ & 1 st der. & 8 & 0.9999 & 0.0073 & 0.9965 & 0.00835 & 0.9999 & 0.0000504 & 0.9962 & 0.000458 \\
\hline & $3004-974$ & Normal & 10 & 0.9999 & 0.00110 & 0.9958 & 0.00444 & 0.9999 & 0.0000591 & 0.9980 & 0.000155 \\
\hline & $3004-974$ & 1 st der. & 5 & 0.9998 & 0.00228 & 0.9676 & 0.0152 & 0.9998 & 0.000152 & 0.9725 & 0.001100 \\
\hline & & & & & & & & & & & \\
\hline & 3024-2497 and 1538-916 & Normal & 6 & 0.9986 & 0.00532 & 0.9761 & 0.00623 & 0.9991 & 0.000303 & 0.9796 & 0.000536 \\
\hline & $3024-2497$ and $1538-916$ & 1 st der. & 6 & 0.9999 & 0.00107 & 0.9967 & 0.00947 & 0.9998 & 0.000139 & 0.9928 & 0.000597 \\
\hline & $2344-844$ & 1 st der. & 10 & 0.9983 & 0.00589 & 0.9761 & 0.0199 & 0.9985 & 0.000388 & 0.9786 & 0.0031 \\
\hline & $2344-844$ & Normal & 10 & 0.9999 & 0.00114 & 0.9976 & 0.00617 & 0.9999 & 0.0000628 & 0.9990 & 0.000246 \\
\hline \multirow{9}{*}{ PCR } & $2344-844$ & Normal & 10 & 0.9978 & 0.00678 & 0.8838 & 0.00977 & 0.9978 & 0.00678 & 0.8838 & 0.00977 \\
\hline & $2344-844$ & 1 st der. & 10 & 0.9983 & 0.00595 & 0.9763 & 0.0202 & 0.9985 & 0.000393 & 0.9787 & 0.00133 \\
\hline & $3024-2497$ and $1538-916$ & 1 st der. & 10 & 0.9990 & 0.00464 & 0.9841 & 0.0120 & 0.9992 & 0.000287 & 0.9845 & 0.000693 \\
\hline & $3024-2497$ and $1538-916$ & Normal & 6 & 0.9975 & 0.00715 & 0.9784 & 0.9784 & 0.00715 & 0.9984 & 0.000402 & 0.0000554 \\
\hline & & & & & & & & & & & \\
\hline & $1504-844$ & 1 st der. & 5 & 0.9974 & 0.00722 & 0.9908 & 0.0140 & 0.9981 & 0.000438 & 0.9908 & 0.000893 \\
\hline & $1504-844$ & Normal & 5 & 0.9974 & 0.00741 & 0.9590 & 0.00526 & 0.9981 & 0.000445 & 0.9740 & 0.000289 \\
\hline & 3004-974 & Normal & 10 & 0.9980 & 0.00646 & 0.9307 & 0.00881 & 0.9986 & 0.000376 & 0.9575 & 0.000597 \\
\hline & 3004-974 & 1 st der. & 10 & 0.9981 & 0.00627 & 0.9785 & 0.0194 & 0.9984 & 0.000403 & 0.9799 & 0.00127 \\
\hline
\end{tabular}

1 st der $=$ first derivative spectra; RMSEC $=$ root mean square error of calibration; RMSEP $=$ root mean square error of prediction; $R^{2}=$ coefficient of determination.

\section{Chemometrics analysis}

Multivariate analysis of PLS and PCR was established using TQ Analyst software version 7.0 (Thermo electron Corporation, Madison, WI) included in instrument of FTIR spectrophotometer. PLS and PCR calibrations were used for developing model which correlated between actual values of curcumin (CUR) and desmethoxycurcumin (DMC) obtained from HPLC determination and FTIR predicted values. Some statistical parameters namely coefficient determination $\left(R^{2}\right)$, Root Mean Square Error of Calibration (RMSEC) and Root Mean Square Error of Predicted (RMSEP) were computed using TQ Analyst.

\section{RESULTS AND DISCUSSION}

HPLC method is method of choice for quantitative analysis of curcuminoid due to its capability to make separation among curcuminoid components. In this study, FTIR spectroscopy combined with multivariate calibration was proposed as an alternative technique to HPLC method due to its simplicity in sample preparation. The analytical results obtained from HPLC measurement was used as actual values of CUR and DMC during analysis using FTIR spectroscopy. Two multivariate calibrations, namely partial least square (PLS) and principle component regression (PCR) were used for modelling the correlation between actual values of CUR and DMC in syrup samples containing Curcuma extract (Curcuma longa and or Curcuma xanthorriza) as determined by HPLC with predicted values using FTIR spectroscopy at optimized wavenumbers region. Table 1 compiled the contents of CUR and DMC in syrup samples, analyzed using HPLC previously validated by our laboratory (Prabaningdyah et al., 2017). Typical chromatogram of evaluated syrup samples was shown in Figure 2. It can be shown that peaks of CUR and DMC were well resolved from other components.

Figure 3 exhibited FTIR spectra of syrup samples containing Curcuma extract which showed typical absorption bands of curcuminoid. The interpretation of functional groups responsible for IR absorption in syrup samples could be correlated with functional groups in curcuminoid (CUR and DMC). Wide and intense absorption at $3265 \mathrm{~cm}^{-1}$ corresponded to the stretching vibration of the $\mathrm{OH}$ bond ( $-\mathrm{OH}$ stretching) and was associated with the presence of hydrogen bond. The absorption peaks at 2960 
and $2922 \mathrm{~cm}^{-1}$ were coming from $\mathrm{CH}_{3}$ - and $\mathrm{CH}_{2}-$ asymmetric stretching vibrations, respectively. The intense and characteristics peak at $1639 \mathrm{~cm}^{-1}$ corresponded to conjugated carbonyl $(\mathrm{C}=\mathrm{O})$
(Rohman et al., 2015). These absorption peaks proved that main components in syrup samples was curcuminoid.

Table 3: Difference between actual and calculated curcuminoid content in syrup using PLS multivariat calibration assisted with TQ Analyst software.

\begin{tabular}{|c|c|c|c|c|c|c|}
\hline \multirow{2}{*}{ Index } & \multicolumn{3}{|c|}{ Curcumin } & \multicolumn{3}{|c|}{ Demethoxycurcumin } \\
\hline & Actual (mg/g) & Calculated (mg/g) & Diff. $x$ Path & Actual (mg/g) & Calculated (mg/g) & Diff. $x$ Path \\
\hline 1 & 0.1841 & 0.18281 & -0.00129 & 0.01278 & 0.0127 & -0.00008 \\
\hline 2 & 0.2677 & 0.26643 & -0.00127 & 0.0192 & 0.01911 & -0.00009 \\
\hline 3 & 0.3203 & 0.3194 & -0.0009 & 0.0226 & 0.02254 & -0.00006 \\
\hline 4 & 0.1414 & 0.14379 & 0.00239 & 0.01005 & 0.0102 & 0.00014 \\
\hline 5 & 0.2364 & 0.23739 & 0.00099 & 0.01644 & 0.0165 & 0.00006 \\
\hline 6 & 0.2532 & 0.25315 & -0.00005 & 0.01754 & 0.01754 & 0 \\
\hline 7 & 0.1414 & 0.14017 & -0.00123 & 0.01005 & 0.01001 & -0.00004 \\
\hline 8 & 0.23645 & 0.23471 & -0.00174 & 0.01644 & 0.01635 & -0.00009 \\
\hline 9 & 0.18406 & 0.18344 & -0.00062 & 0.01278 & 0.01274 & -0.00004 \\
\hline 10 & 0.2364 & 0.23728 & 0.00088 & 0.01644 & 0.0165 & 0.00006 \\
\hline 11 & 0.09767 & 0.09797 & 0.0003 & 0.00706 & 0.00706 & 0 \\
\hline 12 & 0.25323 & 0.25378 & 0.00056 & 0.01754 & 0.01759 & 0.00005 \\
\hline 13 & 0.2532 & 0.25223 & -0.00097 & 0.01754 & 0.01748 & -0.00006 \\
\hline 14 & 0.093 & 0.09201 & -0.00099 & 0.00665 & 0.00661 & -0.00004 \\
\hline 15 & 0.14145 & 0.14096 & -0.00049 & 0.01005 & 0.01004 & -0.00001 \\
\hline 16 & 0.093 & 0.09341 & 0.00041 & 0.00665 & 0.00667 & 0.00002 \\
\hline 17 & 0.32031 & 0.32058 & 0.00027 & 0.0226 & 0.02261 & 0.00001 \\
\hline 18 & 0.09303 & 0.09268 & -0.00036 & 0.00665 & 0.00662 & -0.00003 \\
\hline 19 & 0.1841 & 0.18447 & 0.00037 & 0.01278 & 0.01283 & 0.00004 \\
\hline 20 & 0.0977 & 0.09921 & 0.00151 & 0.00706 & 0.00713 & 0.00007 \\
\hline 21 & 0.0977 & 0.09679 & -0.00092 & 0.00706 & 0.00699 & -0.00007 \\
\hline 22 & 0.2677 & 0.27031 & 0.00261 & 0.0192 & 0.0193 & 0.00011 \\
\hline 23 & 0.3203 & 0.32058 & 0.00028 & 0.0226 & 0.02265 & 0.00004 \\
\hline 24 & 0.0698 & 0.06732 & -0.00248 & 0.00503 & 0.0049 & -0.00013 \\
\hline 25 & 0.03272 & 0.03857 & 0.00585 & 0.00244 & 0.00252 & 0.00008 \\
\hline 26 & 0.0327 & 0.03546 & 0.00276 & 0.00244 & 0.00237 & -0.00007 \\
\hline 27 & 0.0262 & 0.0252 & -0.001 & 0.00177 & 0.0017 & -0.00007 \\
\hline 28 & 0.0698 & 0.06474 & -0.00506 & 0.00503 & 0.00473 & -0.0003 \\
\hline 29 & 0.02618 & 0.02534 & -0.00085 & 0.00177 & 0.00173 & -0.00004 \\
\hline 30 & 0.06982 & 0.07047 & 0.00065 & 0.00503 & 0.00508 & 0.00005 \\
\hline 31 & 0 & 0.00108 & 0.00108 & 0 & 0.00005 & 0.00005 \\
\hline 32 & 0.02618 & 0.02741 & 0.00123 & 0.00177 & 0.00183 & 0.00006 \\
\hline 33 & 0 & 0.00089 & 0.00089 & 0 & 0.00003 & 0.00003 \\
\hline 34 & 0.0327 & 0.03768 & 0.00498 & 0.00244 & 0.00239 & -0.00006 \\
\hline 35 & 0 & -0.00162 & -0.00162 & 0 & -0.00006 & -0.00006 \\
\hline 36 & 0.26774 & 0.26758 & -0.00016 & 0.0192 & 0.01919 & -0.00001 \\
\hline
\end{tabular}

For quantitative analysis, the selection of wavenumbers region was critical point during developing PLS and PCR models. The selection of wavenumbers region was based on its capability to provide the highest coefficient determination $\left(R^{2}\right)$ and lowest errors expressed by RMSEC and RMSEP. To facilitate optimum model, FTIR spectra were also subjected to first derivative. Table 2 compiled the performance of PLS and PCR models using normal and first derivative spectra for the prediction of CUR and DMC in syrup samples along with statistical parameters, including the number of factors, $R^{2}$ in calibration and prediction (validation) models, RMSEC and RMSEP. Based on highest $R^{2}$ and lowest values, FTIR normal spectra at wavenumbers region of 3004-974 $\mathrm{cm}^{-1}$ using PLS calibration was selected for quantitative analysis of CUR and $\mathrm{DMC}$ in the syrup samples. Table 3 described difference between actual CUR and DMC from HPLC analysis and calculated CUR and DMC content in syrup using PLS multivariat calibration assisted with TQ Analyst software. 


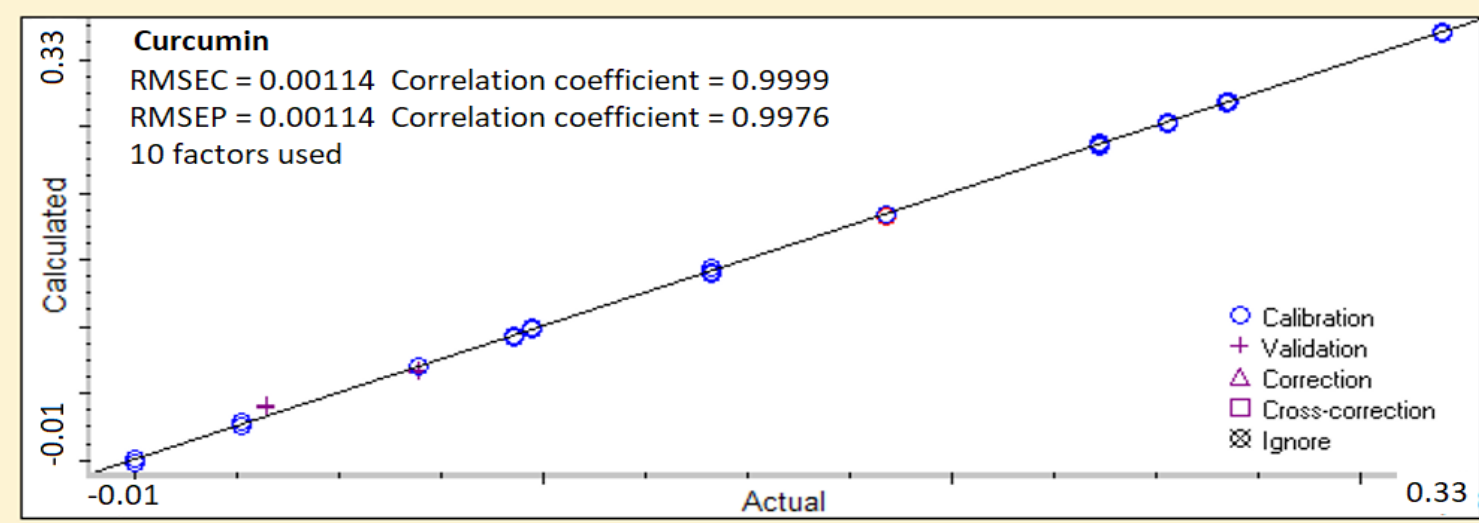

(A)

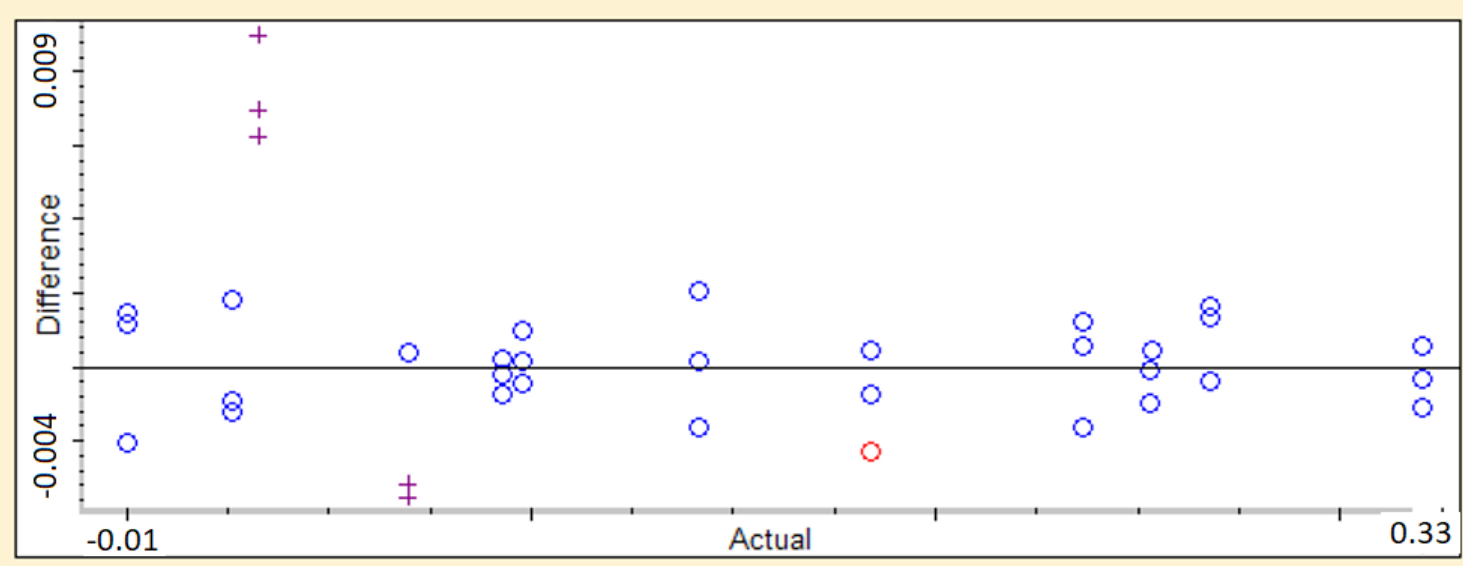

(B)

Fig. 4: The PLS calibration model for the relationship between actual values of curcumin and FTIR predicted value. (A) calibration model; (B) residual analysis.

Figure 4 exhibited the correlation between actual values of CUR determined by HPLC method and FTIR predicted values using optimized wavenumbers. The $R^{2}$ values obtained were 0.9999 (calibration) and 0.9976 (prediction). The errors in calibration (RMSEC) and validation (RMSEP) were relatively low, i.e. RMSEC of $0.00114 \%$ and RMSEP of $0.001167 \%$. From residual analysis (Figure 4B), it is clear that systematic error did not occur because the residual value fall above and below zero value. Similarly, Figure 4 revealed correlation between the actual contents of DMC and predicted values using FTIR spectroscopy with high $R^{2}$ and low errors. Based on $R^{2}$, RMSEC and RMSEP, FTIR spectroscopy using PLS model was accurate and precise method for prediction of CUR and DMC in syrup samples. FTIR spectroscopy method is fast and reliable method for routine quality control of syrup formulation containing Curcuma extract.

\section{CONCLUSION}

FTIR spectroscopy using normal spectra at wavenumbers region of 3004-974 $\mathrm{cm}^{-1}$ coupled with PLS model was accurate and precise for determination of CUR and DMC in syrup formulation containing Curcuma extract. This method can be used as an alternative HPLC method suitable for routine monitoring of herbal medicine in which curcuminoid is main components. The developed method is fast, efficient and not involving chemical and reagents, therefore, FTIR spectroscopy in combination with PLS is considered as green analytical method.

\section{CONFLICT OF INTEREST}

The author declares no conflict of interest.

\section{ACKNOWLEDGEMENT}

The authors thank to the Ministry of research and higher education for financial support during this study with contract number of 2328/UN1.P.III/DIT-LIT/LT/2017 awarded to Abdul Rohman, Ph.D. The National Agency of Drug and Food Control, District of Yogyakarta, Republic of Indonesia was acknowledged for HPLC facilities make this study possible, PT. SOHO Pharmaceutical Industry was acknowledged for supporting sample placebo. 


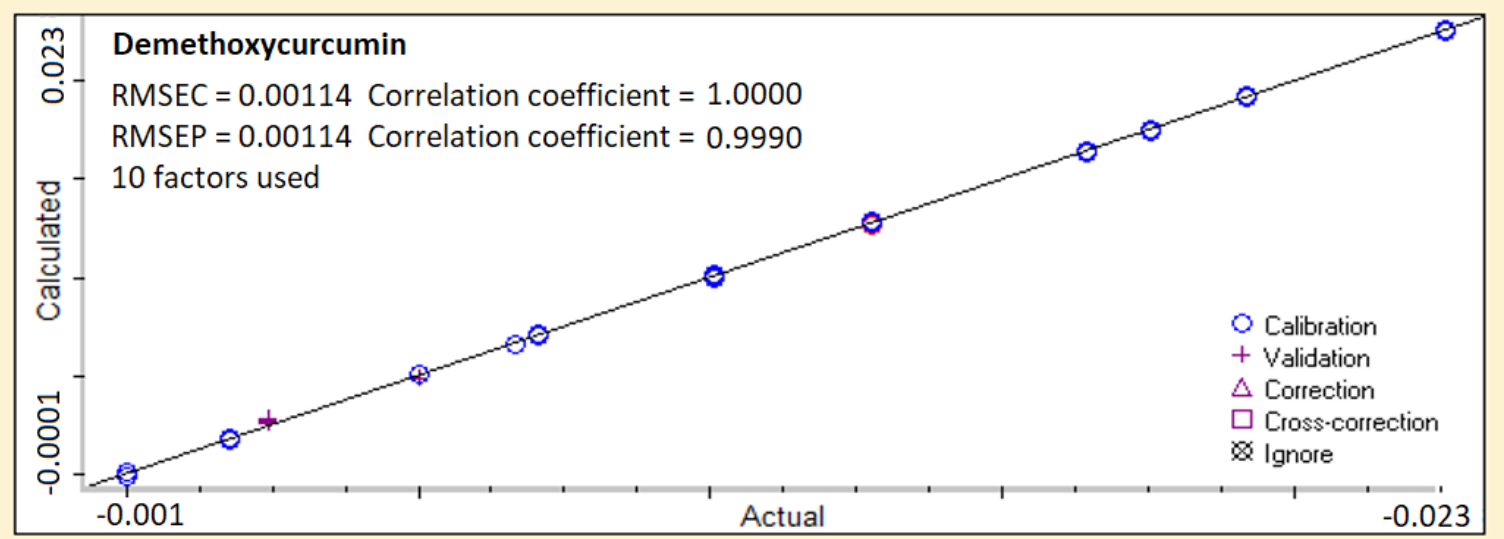

(A)

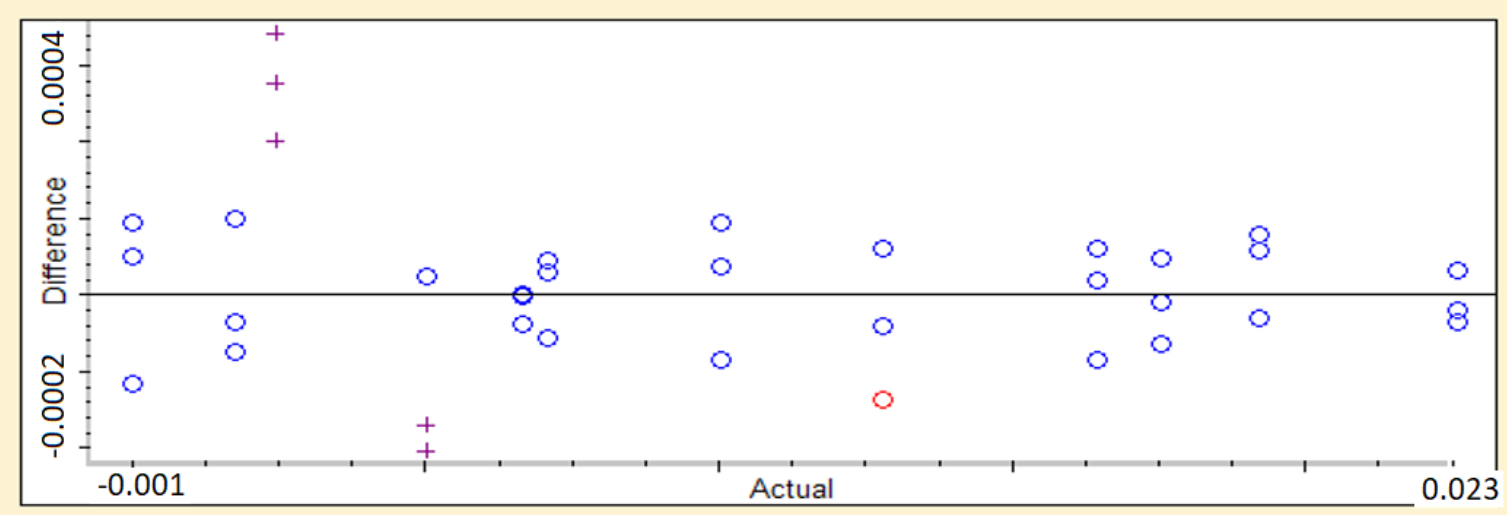

(B)

Fig. 5: The PLS calibration model for the relationship between actual values of demethoxycurcumin and FTIR predicted value. (A) calibration model; (B) residual analysis.

\section{REFERENCES}

Anubala S, Sekar R, Nagaiah K. Determination of Curcuminoids and Their Degradation Products in Turmeric (Curcuma longa) Rhizome Herbal Products by Non-aqueous Capillary Electrophoresis with Photodiode Array Detection. Food Anal. Methods 2016; 9, 2567-2578. https://doi. org/10.1007/s12161-016-0438-1.

Duvoix A, Blasius R, Delhalle S, Schnekenburger M, Morceau F, Henry E, Dicato M, Diederich M. Chemopreventive and therapeutic effects of curcumin. Cancer Lett. 2005; 223: 181-190. https://doi.org/10.1016/j. canlet.2004.09.041.

Jiang H, Somogyi Á, Jacobsen NE, Timmermann BN, Gang DR. Analysis of curcuminoids by positive and negative electrospray ionization and tandem mass spectrometry. Rapid Commun. Mass Spectrom. 2006; 20, 1001-1012. https://doi.org/10.1002/rcm.2401.

Korany MA, Haggag RS, Ragab MAA, Elmallah, OA. A validated stability-indicating HPLC method for simultaneous determination of Silymarin and Curcumin in various dosage forms. Arab. J. Chem. 2013; https://doi.org/10.1016/j.arabjc.2013.06.021.

Lechtenberg M, Quandt B, Nahrstedt A. Quantitative determination of curcuminoids in Curcuma rhizomes and rapid differentiation of Curcuma domestica Val. and Curcuma xanthorrhiza Roxb. by capillary electrophoresis. Phytochem. Anal. 2004; 15: 152-158.

Lestari HP, Martono S, Wulandari R, Rohman, A. Simultaneous analysis of Curcumin and demethoxycurcumin in Curcuma xanthorriza using FTIR spectroscopy and chemometrics. Int. Food Res. J. 2017; 24: 2097-2101.

Li S, Yuan W, Deng G, Wang P, Yang P, Aggarwal B. Chemical composition and product quality control of turmeric (Curcuma longa L.). Pharm. Crops 2011; 2: 28-54.

Péret-Almeida L, Cherubino APF, Alves RJ, Dufossé L, Glória MBA. Separation and determination of the physico-chemical characteristics of curcumin, demethoxycurcumin and bisdemethoxycurcumin. Food Res. Int. 2005; 38: 1039-1044. https://doi.org/10.1016/j.foodres.2005.02.021.

Prabaningdyah NK, Riyanto S, Rohman A, Siregar C. Application of HPLC and response surface methodology for simultaneous determination of curcumin and desmethoxycurcumin in Curcuma syrup formulation. J. App. Phar. Sci., 2017; doi: 10.7324/JAPS.2017.71207.

Rohman A. Analysis of curcuminoids in food and pharmaceutical products. Int. Food Res. J. 2012; 19; 19-27.

Rohman A, Ramadhani D, Nugroho A. Analysis of Curcumin in Curcuma longa and Curcuma xanthorriza Using FTIR Spectroscopy and Chemometrics. Res. J. Med. Plant 2015; 9: 179-186. doi:10.3923/ rjmp.2015.179.186. 
Shishodia S. Curcumin: Getting Back to the Roots. Ann. N. Y. Acad. Sci. 2005; 1056: 206-217. https://doi.org/10.1196/annals.1352.010.

Singh VD, Daharwal SJ, Suresh PK. A Review of Instrumental Analytical Methods to Assay Active Ingredients in Multicomponent Pharmaceutical Formulations. Columbia J. Pharm. Si. 2014; 2: 1-14.

Tanaka K, Kuba Y, Sasaki T, Hiwatashi F, Komatsu K. Quantitation of Curcuminoids in Curcuma Rhizome by Near-infrared Spectroscopic Analysis. J. Agric. Food Chem. 2008; 56: 8787-8792. https:// doi.org/10.1021/jf801338e.

\section{How to cite this article:}

Prabaningdyah NK, Riyanto S, Rohman A. Application of FTIR spectroscopy and multivariate calibration for analysis of curcuminoid in syrup formulation. J App Pharm Sci, 2018; 8(03): 172-179. 